https://doi.org/10.3727/152599519X15506259856039

MS 17067 accepted for publication in Event Management

\title{
USING A SPORT EVENT TO CREATE A SENSE OF COMMUNITY: CHARITY SPORT EVENT MANAGER PERSPECTIVES
}

Lead author: Ebe Daigo Ebe Daigo, Assistant Professor, Griffith University and Waseda Institute for Sport Science

Faculty of Sport Sciences, Waseda University

2-7-5 Higashifushimi Nishitokyo-shi, Tokyo 202-0021

Waseda University Higashifushimi campus 75-2 Room 302

Telephone: 042-461-1331(external); Email: e.daigo@aoni.waseda.jp

Corresponding Author: Kevin Filo, Associate Professor, Acting Department Head, Griffith Business School, Department of Tourism, Sport and Hotel Management, Griffith University, Business 2 (G27) Room 3.32, QLD 4222, Gold Coast, QLD 4222 Australia Telephone:+61755528719; Email: k.filo@griffith.edu.au

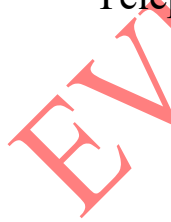

ACKNOWLEDGMENTS

This research was supported by an encourage research grant of Sasagawa Sport Foundation (170B1-017) 


\begin{abstract}
Charity sport events not only involve completing the activity, but also the opportunity to bring people together. A variety of research has examined charity sport events' capacity to foster a sense of community from the participant point of view. The current research examines sense of community within charity sport events from the event management perspective and advances the following research question: What do charity sport event managers feel they have put in place to create sense of community among participants? To address this research question, qualitative data were collected via interviews with 15 charity sport event managers in Japan. An interview guide comprised of six demographic questions, along with nine questions based upon the sense of community in sport framework was utilized. Five themes were identified within the interviews: charitable contribution, soliciting feedback from participants, interactive event environment, supplementary activities, and lack of competition. Two themes from the sense of community in sport framework that did not emerge across the interviews underscore opportunity for event managers to leverage mobile applications and online discussion forums to engage participant's shared interest in sport, as well as enlist leaders among event participants to serve as advocates. Based upon the current results, future research can include managers from the designated charities aligned with events to assess whether the sense of community created within these events leads tolong-term benefits for the organisation.
\end{abstract}

Key words: Charity sport events, Event managers, Sense of community, Event Participation, Philanthropy 


\section{USING A SPORT EVENT TO CREATE A SENSE OF COMMUNITY: CHARITY SPORT EVENT MANAGER PERSPECTIVES \\ INTRODUCTION}

Charity sport events have become established platforms for promoting physical activity, raising awareness and funds for charitable causes, and bringing like-minded people together (Bunds, Brandon-Lai, \& Armstrong, 2016; Filo, Funk, \& O’Brien, 2009; Higgins \& Lauzon, 2003). These events have been subject to an array of academic inquiry, which has suggested that charity sport events can foster a sense of community among participants (Filo, Funk, \& O’Brien, 2008; Filo, Spence, \& Sparvero, 2013). As an illustration of this idea, events have introduced strategies such as novel dress and theming (e.g., Relay for Life, MS Swim-a-thon), encouraging participants to complete the event as part of a team (e.g., Flying Pig Marathon), and marketing campaigns suggesting that individuals who complete the event are part of unique club (e.g., Tough Mudder) to further facilitate sense of community among participants (Filo \& Coghlan, 2016; Filo, Lock, Sherry, \& Hunyh Quang,2018; Olberding \& Jisha, 2005).

Fostering sense of community represents an important potential social contribution for charity sport events. Individuals are becoming increasingly isolated and there has been a pronounced decrease in meaningful, in-person social connections (McPherson, Smith-Lovin, \& Brashears, 2006). The sense of community derived from charity sport events can be utilized to allow participants to meet new people while heightening awareness of social causes and empathy. While academic and practical evidence reinforces the idea that charity sport events can create sense of community, this phenomenon has been examined almost exclusively from the event participant perspective. 
Management's role in fostering community presents a challenging task. Research on brand communities has suggested that management should limit intrusion upon participant communities (Cova \& Pace, 2006). Meanwhile, in the spectator sport context, fan rituals that reflect a communal orientation were met with resistance when driven, or manufactured, by management rather than led by fans (McDonald \& Karg, 2014). Based upon this challenge, as well as calls for investigation of charity sport events from additional stakeholder perspectives (e.g., Coghlan, 2012; Woolf, Heere, \& Walker, 2013), the purpose of the current research is to examine sense of community within charity sport events from the event management perspective.

Warner and Dixon's (2011) sport and sense of community framework guides this investigation. The research context is charity sport events in Japan. This research context was selected because charity sport events have increased in frequency in Japan (Mizumoto \& Okura, 2016), and because these events reflect an ongoing trend to address local challenges through sport in Japan (Takenaka, 2014) such as events being utilised to raise funds in the aftermath of natural disasters (Saito \& Nakamura, 2012). Examining charity sport events in Japan also allows for investigation of these events outside of the Western context, which is where the existing research in this realm has predominantly taken place.

The manuscript is divided into the following sections: first the theoretical framework of sense of community in sport is introduced and reviewed, followed by a review of existing literature on charity sport events and community. Second, the methods employed to collect data are detailed. Third, the results are presented narratively. Finally, the findings are discussed highlighting theoretical and practical contributions, along with suggestions for future research. 


\section{THEORETICAL FRAMEWORK}

\section{Sense of Community in Sport}

Sense of community can be defined as a factor that results in sport participants experiencing sense of belonging and support from others at a level beyond the individual level (Sarason, 1974). Sport is viewed as an outlet from which individuals can derive sense of community because of the collective social experience (e.g., watching a sport event with thousands of others in a stadium) inherent to sport consumption (Warner, Kerwin \& Walker, 2013). Accordingly, community can be viewed as something upon which sport managers can capitalise (Chalip, 2006).

The conceptualisation of sense of community in sport has borrowed from research in education (e.g., Clopton, 2008) and community psychology literature (e.g., McMillan \& Chavis, 1986). To build upon these conceptualisations and develop a sport-specific measurement tool, Warner and colleagues (e.g., Warner \& Dixon, 2011; Warner, Dixon, \& Chalip, 2012; Warner et al., 2013) uncovered seven factors that can lead to community in sport. These seven factors are: administrative consideration, common interest, competition, equity in administrative decisions, leadership, social spaces, and voluntary action. Each of these factors is relevant to the charity sport event context.

Administrative consideration is defined as the expression of care, concern and intention of sport administrators (Warner et al., 2012). In the charity sport event context, this can refer to event management creating a healthy and supportive event environment, along with clarity concerning the fundraising objectives for the event (Filo et al., 2013). Common interest encompasses group dynamics, socialising, and friendships that come from individuals being brought together by a shared interest (Warner et al., 2012). This factor aligns with the common 
bond and connection shared among charity sport event participants based upon the physical activity or benefitting charity (Filo et al., 2008, 2009). Competition refers to individuals positioning themselves against rivals (Warner et al., 2012). Charity sport event participants may complete an event to test themselves physically and see how fast they can finish the challenge (Coghlan, \& Filo, 2013). Equity of administrative decisions represents management decisions that indicate all individuals are treated equally (Warner et al., 2012). This can manifest in charity sport event participants feeling as though they are all working together (Filø et al., 2018).

Leadership opportunities is defined as informal and formal opportunities to lead others within the community (Warner et al., 2012). In the charity sport eyent context, the opportunity to participate as part of a fundraising team (Olberding \& Jisha, 2005; Woolf et al., 2013), and to become a leader within a fundraising team (Filo et al., 2018) encapsulates this factor. Social spaces are areas wherein sport participants can engage and interact with each other (Warner et al., 2012). Communal spaces such as the start and finish line, and post-event celebrations have been highlighted as critical social spaces in the charity sport event literature (Filo et al., 2008, 2013, 2018). Voluntary action involves activities that sport participants engage in on their own without external coercion (Warner et al., 2012). The voluntary nature of charity sport event participation and fundraising aligns with this factor (Higgins \& Lauzon, 2003).

Warner et al. (2013) tested their multidimensional model in the youth sport context and determined this represented a valid and reliable assessment of sense of community. Notably, the authors found that Voluntary Action was not applicable. A six-factor model was then advanced: administrative consideration, common interest, equity in administrative decisions, leadership opportunities, social spaces and competition; while Warner et al. (2013) called for further testing and refinement of this framework across a variety of sport settings. The framework has been 
applied to different contexts, such as small-scale events (e.g., Kerwin, Warner, Walker, \& Stevens, 2015) and to different stakeholders, such as parents in youth sport (e.g., Warner, Dixon, \& Leierer, 2015). Based upon Warner et al.'s (2013) call for further testing, along with the relevance of each factor to events, the current research applies this framework to charity sport events.

Sense of community is a critical contributor to quality of life that has been shown to activate individuals' views of their environment, social relations, and sense of control (Chavis \& Wandersman, 1990). Research has demonstrated that sense of community contributes to wellbeing outcomes, including happiness (Davidson \& Cotter, 1991). Aecordingly, sense of community is a concept that has received increased interest within academic research across a number of disciplines (Ross \& Searle, 2019). The focus on sense of community in research has corresponded with a time when social isolation has increased (Hampton, Sessions, \& Her, 2011). Sport events represent a mechanism that can assist in addressing social isolation (Jarvie, 2003; Peachey, Borland, Lobpries, \& Cohen, 2015), while sense of community is a potential outcome of charity sport events (Filo et al., 2013). The literature on charity sport events and sense of community is reviewed next.

\section{Charity Sport Events}

Sport events are platforms from which sense of community can be developed and promoted (Chalip, 2006). The communal effects of sport events can stem from the specific activity or cause inherent to the event (Misener \& Mason, 2006). In the charity sport event context, the benefitting charity represents an event component from which participants can derive a sense of community. Filo et al. (2008) outlined sense of community as a potential outcome of charity sport participation based upon the interaction between the recreation motives 
and motives for charitable giving driving participation. Extending this, Filo et al. (2009) identified camaraderie, sense of belonging and feeling a part of something bigger than the individual as factors contributing to a meaningful charity sport event experience. Sense of community among participants was investigated specifically by Filo et al. (2013) who revealed that five of the six properties of Geimenschaft (i.e., community): dense and demanding social ties; social attachments to and involvement in institutions; ritual occasions; perceptions of similarity with others; and common beliefs in an idea system, moral order, institution or group; were present for participants in the Lance Armstrong Foundation LIVESTRONG Challenge.

The sense of community derived from charity sport events is well established from the participant perspective. However, an opportunity exists for exploration of how charity sport event managers can foster and activate this sense of community. Suggestions have been made for charity sport event managers to leverage social connectedness among participants to achieve important event objectives (Goodwin, Snelgrove, Wood, \& Taks, 2017). Notably, Chalip, Green, Taks, and Misener (2016) revealed that there is an unfair expectation on event managers to foster social impacts from sport events, such as creating a sense of community. Meanwhile, Filo et al. (2013) challenged researchers to incorporate stakeholder perspectives beyond charity sport event participants in future investigations of community in this context. With this in mind, the current research examines sense of community within charity sport events from the event management viewpoint. Specifically, the following research question is advanced:

Research Question: What do charity sport event managers feel they put in place through the event to create sense of community among participants? 
To address this research question, qualitative data were collected via semi-structured interviews with event managers in Japan. The Japanese charity sport event context is described next. From there, the method employed to collect data is detailed.

\section{Research Context}

The data were collected from charity sport event managers in Japan. The Japanese context was selected due to the growing popularity and increasing charitable inclination in the country. Japan was ranked \#114 (out of 140) in the 2016 Charity Aid Foundation World Giving Index (Charity Aid Foundation, 2016), and has since moved up to \#111 in 2017 (Charity Aid Foundation, 2017). This represents a still growing propensity towards philanthropy. As noted above, charity sport events have become increasingly popular in Japan (Saito \& Nakamura, 2012; Takenaka, 2014). This growth in popularity and frequency can be attributed to a number of factors. First, Japan has been struck by a number of natural disasters in recent years, and sport has been integral in aiding in the recovery (Lankston, 2011). Second, sport events are viewed as increasingly important in Japan, as evidenced by Prime Minister Shinzou Abe's belief that the 2020 Olympics and Paralympics will be a catalyst of Japan's rebirth (Cha, 2016). Third, changes in the Japanese tax code effective from 2012 have incentivised donations to non-profit organisations via charity sport events (Harada, 2015). Collectively, these factors have contributed to the emergence of charity sport events in Japan, and this emergence led to the researcher's belief that Japan represented an appropriate context for the current enquiry.

\section{METHOD}

\section{Participants}

The research team utilised a qualitative research approach with semi-structured interviews with event managers $(\mathrm{N}=16)$. Interviews were deemed appropriate due to the 
flexibility provided which allowed for accommodating the event manager's busy schedules (Rabionet, 2011). Two interviews were conducted via the telephone, while thirteen interviews were conducted in person. Nine interviewees were male, while seven were female. Interviewees ranged in age from 20-60, with the highest proportion in their 40s $(n=6)$. Fourteen interviewees had obtained at least a Bachelors' degree. See Table 1 for a demographic breakdown of the interviewees, along with information about the sport activity and benefitting charities for each event.

\section{$<<<$ INSERT TABLE 1 HERE $>>>$}

\section{Procedures}

To identify potential events and interviewees, two database searches were employed, Google and KIKUZO (a Japanese newspaper archive system), utilising the keywords 'charity sport event 2016'. This search identified 36 events, however 11 of these events were spectator events rather than participatory events, hence deemed unsuitable for the current research. Of the 25 remaining events, three were managed by the same individual, while four events did not have a designated charity (or charities) upon further examination. In total, 20 event managers were identified as suitable interviewees for the current research.

In December 2016 an email invitation to participate in the current research was sent to the event organisers for each of the 20 charity sport events identified, and 16 event managers representing 15 charity sport events responded indicating their willingness. In the context of the current research, event managers refer to the person in charge of the event. This includes job titles such as: event manager, event director, and head of staff. Each of these roles was considered an event manager due to their responsibility. From there, an online questionnaire was sent to each event manager (two event managers were co-managers of the same event and data 
were collected from them together). This online questionnaire had two purposes: 1) to gather information concerning the background and profile of the event; and b) to identify a date and time that was most convenient for the event manager to conduct the interview.

The interviews took place in April 2017 and each interview was conducted in Japanese and lasted 45-60 minutes. The interviews were conducted by a member of the research team, along with a research assistant. Upon completion of the interviews, the recordings were transcribed in Japanese by a third-party transcription company. The transcription and translation of the semi-structured interview data occurred in multiple stages. First, the Japanese interview recordings were transcribed in Japanese by a transcription company. Second, the Japanese version of the transcripts was forwarded to the interviewees to confirm the data to be used for the analysis.

After transcribing all the recorded interviews, the Japanese transcripts were forwarded to a translation company. The translation was completed in three weeks. After receiving the translation of each transcript, a back translation process was conducted and managed by a linguistics lecturer and a bilingual doctoral student. The back translation method uses at least two bilingual translators who are familiar with the source and target language (Su \& Parham, 2002). The back translation process took one month to complete. After receiving each translated transcript, a Japanese member of this research team reviewed each document by rereading the original Japanese version and reading the translated version to check whether there were discrepancies between the two. There were no major issues with interpretation found in the English transcripts. 


\section{Materials}

The interview guide consisted of three sections. First, a collection of demographic questions (e.g., age, gender, education level, number of years working for the event) were included to provide a biographical sketch of each interviewee. Second, a series of questions were developed based upon the six factors underscoring sense of community in sport as advanced by Warner et al. (2013): administrative consideration, common interest, equity in administrative decisions, leadership opportunities, social spaces, competition. Example questions include: 'How do you design your event to facilitate interaction and socialising among event participants?' (Social Spaces) and 'How would you describe your efforts to solicit opinions from event participants on how the event is designed and delivered?' (Ceadership Opportunities). Third, four questions concerning: event objectives, the strengths of the event, and challenges the event management team had been experiencing concluded the interviews to provide a broader overview of each event. In total, the interview guide consisted of six demographic questions, along with eleven questions open-ended questions. The full interview guide is included in the appendix.

\section{Data Analysis}

At the conclusion of the interviews, transcription and translation process, the transcriptions were then analysed thematically, which consisted of six steps: (1) getting familiar with the data; (2) generating initial codes; (3) searching for themes; (4) reviewing themes; (5) defining and naming themes; and (6) producing the report (Braun \& Clarke, 2006).

In getting familiar with the data (step 1), one member of the research team repeatedly read the transcriptions, while applying Warner and Dixon's (2011) sport and sense of community as a guiding framework to generate initial codes (step 2) (Miles \& Huberman, 1994). To align 
with Warner and Dixon's (2011) framework, interviewee discussion concerning communication between managers and participants, unity, competition at the event, organisational decision making, and socialising at the event were coded as factors that addressed our research question.

Through this process of generating codes, five themes were identified (step 3). The themes were: charitable contribution, soliciting feedback from participants, interactive event environment, supplementary activities, and lack of competition. The five themes identified were then reviewed by the remainder of the research team (step 4). Specifically, the lead analyst provided the research team with each theme name, the corresponding operational definition, and example representative quotations, to confirm the themes and passages were accurate reflections. There was agreement among the researchers concerning the themes, definitions, and the corresponding quotations, suggesting intercoder reliability (Kurasaki, 2000).

From there, the research team confirmed the name and definition for each theme (step 5), while reviewing the transcripts for additional quotes to reflect each theme. Reviewing each theme for overlap and homogeneity then followed. The results are reported in the section below (step 6) and the themes are described narratively alongside illustrative quotations. Collectively, the results address the research question.

Member checks (e.g., Lincoln \& Guba, 1985) were conducted during the data collection process to ensure the validity of the data. The broader ideas discussed in each interview were shared with the interviewees at the end. Specifically, a summary discussion with each interviewee was conducted to allow individuals to assess the adequacy of the interviewer's understanding. 


\section{RESULTS}

The five themes uncovered within the interviews are described below. Each theme is introduced and operationally defined, followed by supporting quotes from interviewees that reflect each factor. The interviewees are identified by the letter 'I' followed by his/her assigned interview number (reflecting the sequencing of interviews). For instance, the sixth interviewee is identified as I6.

\section{Charitable Contribution}

The first theme to emerge in the interviews was charitable contribution, wherein event managers highlighted the importance of the event as a mechanism to support a charity and give back. Within the context of the current research, this theme is defined as: the event as a means to support a specific charity, but also to broadly educate people about charitable causes in order to inspire and motivate them to give back, as well as to develop empathy among participants. This focus on giving back is exemplified by I4, who stâted: “An event like this becomes an opportunity to get involved in volunteering; you can't think of a thing like this in terms of money, it's the building of the community to support and accept refugees." I2 described the objective of building empathy through his event: "I want to provide an opportunity for people without a disability to think about disabilities." The event managed by I10 features a lap specifically devoted to cancer survivors, and she highlighted how this part of the event brought participants together and provided inspiration: "Seeing cancer patients walk, other participants get inspired, encouraged and further interested in supporting cancer survivors."

I6 indicated that transparency was an important aspect of their event's charitable contribution: "So we hold events, raise money, and send the money to the children all by ourselves without having anyone in between in order to make it transparent." Transparency was 
revealed as an obligation by I15: "We want to publicise, as a charity community, that the donations we received from the participants are put to good use.” The importance of being transparent with charitable support was further underscored by I5: "We used $90 \%$ of the entire revenue for charity. It's really hard to find organizations that use $90 \%$ of the revenue because it costs so much to run events." I9 shared a similar sentiment when asked about the most important objective for the event: "It's easy for participants to see how their money is spent, which is very important. If it's unclear how the money is spent, the charity probably won't last." I13 indicated that providing specific details concerning how money was spent was imperative and garnered a favourable response from participants:

I believe it's important that we give a clear idea of who the recipients are, and how the donation is spent...' they bought a heater for a temporary house with my $¥ 10,000 ’$ sounds a lot more specific and real and gives participants the sense of contribution.

The charitable aspect of the event was described as central component of the event that brought participants closer while bringing attention to the notion of giving back. I1 stated: "We also learned they [participants] gained some satisfaction by contributing to a charity. I believe that the sense of belonging as participants is filled." The centrality of the charity in bringing participants together was portrayed by I8:

The best thing about this event is to be able to spread the [charity's] campaign by having a strong sense of community. We also want them to know that their actions can make others' situations better, such as women in developing countries.

\section{Soliciting Feedback from Participants}

Soliciting feedback from participants was cited as an essential and challenging mechanism for fostering sense of community. This theme is defined as: the importance of 
communicating with event participants before and after the event, while also struggling to identify the best method for gathering input. The importance of soliciting feedback from participants was described by I3 as a critical mechanism in not only understanding participants, but also recruiting sponsors:

After the event, we ask the participants to answer the questionnaire using Google Form, where we get the information on the participants' satisfaction and attributes. The results of the questionnaire are used when we visit and negotiate with potential supporting companies the next year.

I14 indicated that soliciting feedback was critical for a successful event, and referred to a number of platforms that were used:

We utilise Facebook, our homepage, blog, and Instagram. We get feedback using questionnaires. After the event, we distribute the questionnaire form attached to the thank you email. Comments and questions through Facebook or our homepage are dealt with by a designated person in charge.

Similarly, I8 detailed the variety of mechanisms used to engage with participants before, during and after the event:

We use social networking sites (SNS) such as Facebook, Instagram, and Twitter. We use Instagram most recently. We often reply, repost and communicate with participants through SNS. At first, we often used Facebook and used Instagram only for posting images, but this year we shifted to Instagram because more people look at it nowadays. I1 1 reinforced that online was the best mechanism for direct communication with event participants: "I check participants' complaints on Facebook. Not many of them tell us face-toface...Participants can also leave messages on our homepage or on Facebook messenger.” 
Overall, event managers were in agreement that soliciting feedback from participants was compulsory for bringing participants together and ensuring that participant voices are heard.

\section{Interactive Event Environment}

The third theme uncovered within the interviews was interactive event environment, wherein event managers described the various strategies and efforts employed to allow participants to socialise on the event grounds. This theme is defined as: the event design as a mechanism to bring people together, including individuals who have never met before the event. The centrality of interaction among participants within the event is communicated by I10: "We are offering opportunities for many people to meet someone new. Some even hit it off so well for the first time and looked like they're good friends. I think that's a wonderful thing." Facilitating participants meeting new people informed how the event was structured by I10 and her team: "We provide for participants to interact with each other over a cup of tea. Those who come here start talking with each other rather easily." Specific strategies within event design to ensure that participants met new people were further detailed by I3:

All participants get divided into six teams (or colours). No matter how many people you enroll in the event, whether you're a group of 20 people, a couple of people, or even alone, you all belong to a certain team. To avoid having a bunch of people who already know each other in a team, we randomly divide participants [into groups].

Interaction on the event grounds was mentioned by 19: "They [participants] seem to find opportunities to interact with others." Meanwhile, I8 described how participants built upon their networks to meet new people: "In general, people get to know somebody new from their friends or acquaintances, and that is how new relationships are built quickly." She further elaborated that the event is designed to foster a supportive environment among teams on the course: 
"Participants from different teams often communicate with each other in the booth. They nicely ask questions and give some advice to each other to make a good atmosphere." Smaller scale training sessions were organised by I6 in advance of the event to facilitate interaction and allow participants to meet one another in advance of the event:

The training sessions are free of charge. We had about 10 people at one session. Ten people is not a big number, but it led to an interesting story. One out of the ten was actually a well experienced runner who completed a full marathon previously. This person attended the event hoping to meet other runners. In the group of ten people, we also had two people who had no experience running long distances. The three, an experienced runner and two beginners, hit it off immediately. Then the experienced runner decided to make the two beginners complete the marathon. After that, they met for practice several times. Finally, at the event, they ran together from start to finish, and completed the marathon!

The importance of creating an interactive event environment was summarised by I1 describing one of the key outcomes of the event as: "The potential of providing opportunities to those who are regularly jogging every day to meet new people by attending this charity marathon.”

\section{Supplementary Activities}

Building upon the efforts made to facilitate interactivity among participants within the event, managers outlined a number of supplementary activities that were built into the event experience to further foster community. This represents the fourth theme derived from the interviews. Supplementary activities are defined as: activities surrounding the event that promoted novelty and inclusiveness among participants. I4 listed a collection of activities that were incorporated within the event to bring people together: "We set up a photo booth. We sell 
merchandise, and even drinks like beer. We did a dress-up once too. We give quizzes while running." Novelty was explicitly touched upon by I9: "We ask every participant to wear a Santa Claus costume, so it automatically creates a sense of unity among participants." The idea of supplementary activities promoting unity among participants was also alluded to by I15: "We had a singing performance so that everyone can feel that they are in this together."

Meanwhile, I3 detailed activities that were created to allow participants to feel more comfortable and welcome:

They think they're not fit enough take part in such events, and are too worried to join in. So we made up some kinds of activities that don't require such people to engage in physically tough sports. What we had last year was a cheering contest, which is similar to the ones at high and junior high schools in Japan. It created a sense of togetherness and went very well.

I5 detailed how the organisers created an actiyity so parents with young children did not feel excluded: "We always have a walking event every time where parents can join with their children even using baby strollers."

Before and after the event were mentioned as important points for supplemental activities. Pre-event initiatives allowed I8 to differentiate her event:

Before running, participants can enjoy a variety of booths at the indoor main venue of the event. There is a photo booth, a beauty booth, and a body-check booth... Our booths usually have a long line but that is because we provide something special.

Post-event supplemental activities were highlighted as critical means to bring participants together. I13 described the post-event scene: “After running, we lay sheets on the grass and have a little fashion show and eat something, and participants enjoy themselves there." The 
importance of post-event supplementary activities was reinforced by I7: "What I personally think that's good is there are many things that happen after the event... We made a café space with free coffee...there were great talks and conversations between people and groups." Further, I12 revealed: "After the running event, we have a regional dance performance which participants can join in.” Dancing as a means to bring participants together was also referenced by I11:

The first time we had the dance event, it was turned into a flash mob of 'Thriller' since the day was Halloween. This activity allowed people who don't play soccer or futsal to attend the event, donating, dancing and feeling the sense of unity.

Collectively, the results reveal that supplementary activities were frequently used and highly successful in promoting community among participants.

\section{Lack of Competition}

The fifth and final theme to emerge from the interviews was lack of competition. This theme is conceptualised as: an emphasis on minimising competition within the event, instead focusing on having fun and encouraging participants to support one another. Every event manager interviewed discussed how they purposefully designed their event to not be competitive. I7 attributed the lack of competition on the charitable nature of the event: "I don't want people to feel competitive and aggressive like sports in this event. So, we say 'fun run' instead of just 'run. There are many patients fighting with cancer in participants, so we are eliminating all competitive factors." Similarly, I5 alluded to the charity as a factor that distinguishes the event from a more traditional competition:

I don't consider our event as competition. Our event is basically a charity event, so I don't even use facilities to strictly time records... To those who would only like to compete, I would say they should find another event. 
The idea that participants looking for a competitive event were better suited to look elsewhere was also advanced by I6: “To be honest, the purpose of this event is not to satisfy serious runners." He later added: "So we don't take competition seriously here."

I1 described the lack of competition in the event succinctly: "We do not suggest or aim for any competition from our management side." I11 was also concise: “Overall, we don’t really do it competitively." A sentiment shared by I9: "It's better that we make it less competitive." The role of having fun in limiting competition was alluded to by I15: "We focus more on the fun of running rather than its competitive aspect." While I4 expressed how the emphasis on fun prevented the event from taking on a competitive nature: "We don't really focus on the competitive aspect of the run. We're not clocking the runners The participants just want to have fun participating." A focus on fun instead of competition was further reiterated by I8: "We call our event a 'charity fun run' and having fun is the most important thing. We do not want everybody to care too much about it [timing]."

Meanwhile, select event managers mentioned that there was some degree of competition and prizes for top finishers, but these were offset by a diverse set of prizes for all participants. I2 explained:

We prepare not only the regular first, second, and third place prizes based on their time records, but also a variety of prizes since there are a variety of teams such as children and family teams...If the date of the event is May $24^{\text {th }}$, we prepare a prize for a participant who finishes $24^{\text {th }}$. We also give a birthday prize for participants whose birthday is the day of the event. We give a youngest prize for the youngest team of the day... We think about a variety of prizes in this way.

I13 shared a similar story of utilising prizes in a non-competitive manner: 
We record the result since it's a 'race', but there are runners who enjoy chatting with friends and taking pictures together during the race and finish late. So I don't think the element of competition is strong. Although we award the winners, we don't focus on the competition much. For example, we designed a lottery in a way that the best prize can go to anyone. Unlike usual marathon competitions, fastest runners don't always get the best prize. It's not our style.

Through reinforcing the charity, focusing on having fun, and incorporating novelty through prizes, charity sport event managers made it clear that a lack of competition was imperative for bringing people together through their events.

\section{DISCUSSION}

The current research utilised semi-structured interviews to examine sense of community within charity sport events from the event management perspective. Specifically, the following research question was advanced: What do charity sport event managers feel they have put in place to create sense of community among participants? Five themes were uncovered in the interviews: charitable contribution, soliciting feedback from participants, interactive event environment, supplementary activities, and lack of competition. Collectively, the charity sport event managers interviewed discussed bringing participants together in an inclusive and noncompetitive atmosphere wherein they can share their opinions and learn more about empathy and giving back. This aligns with the sense of belonging and support beyond the individual referred to in Sarason's (1974) definition of sense of community. Meanwhile, these themes align with some of the factors underlying sense of community in sport (Warner et al., 2013). The current research represents early exploration of an expanding phenomenon in Japanese culture (i.e., charity sport events) (Mizumoto \& Okumura, 2016). The themes uncovered share a number of 
similarities with research within this same context based in North America and Europe, with some differences potentially related to nuances of Japanese culture.

Charitable contribution shares similarities with administrative consideration.

Administrative consideration is embodied by the care, concern and intentionality of sport administrators that goes beyond the sport experience to contribute to a sense of community among participants (Warner \& Dixon, 2011). This factor speaks to care and support for members of the community (Warner et al., 2013). Similarly, the theme of charitable contribution revealed that event managers positioned their event as a mechanism to support a specific charity while also giving back to the local community more broadly and educating community members on the needs of others. Stimulating interest in charitable activity has been highlighted as an important outcome of charity sport events (Goodwin et al., 2017).

The theme of charitable contribution also shares similarities with participant motives such as need to help others and desire to improve the charity, which were found to contribute to communitas at charity sport events (Filo et al., 2008). Also, event managers describing this factor speaks to enhancing understanding of participants' duty of care in getting involved in these events (Bennett, Mousley, Kitchin, \& Ali-Choudhury, 2007). In addition, the notion of giving back and developing empathy evident within charitable contribution is also closely aligned with the concept of dense and demanding social ties, a property of Geimenschaft (Tonnies, 1974), wherein participants represent a collective action network in which individuals feel an obligation to act on behalf of the charity and spread the word. This property has been previously uncovered in the charity sport event context (Filo et al., 2013). The emergence of this theme within the current research aligns with an increased emphasis on fundraising and charitable contributions through sport currently taking place in Japan (Harada, 2015; Saito \& Nakamura, 2012). 
Soliciting feedback from participants runs parallel with equity in administrative decisions (Warner et al., 2013). Equity in administrative decisions encompasses perceived fairness and justice in management decisions among sport participants (Warner \& Dixon, 2011).

Consideration of the needs of all sport participants is a component of this factor (Warner et al., 2013). To this end, the charity sport event managers interviewed indicated that seeking input and feedback from event participants was central to decisions that were made for future events and allowed for understanding of participants needs. The number of tools used to do so further underscores the importance of this initiative. Seeking and implementing feedback from participants by event managers demonstrates sport event participants can be co-creators of social value with event organisers (Woratschek, Horbel, \& Popp, 2014). Notably, event managers outlined challenges in this process including a poor response rate, low quality data, and confusion regarding which platform was the most effective tool. This suggests that further efforts are needed to optimise this co-creation and aspect of the community. The issues event managers outlined in identifying the appropriate social media tools to collect feedback from participants reinforces the challenges in the proactive use of social media to engage with participants (Pasanen \& Konu, 2016).

Interactive event environment is a theme that does not necessarily align with a factor from Warner et al.'s (2013) framework. Designing the event to bring people together and allow individuals who had never met before to meet stands separate from factors previously outlined in the sense of community in sport literature (Warner \& Dixon, 2011). However, this theme does align with factors that drive participants to get involved with these events, such as the social motive, which was previously found to contribute to communitas (Filo et al., 2008). In addition, the interactivity inherent to this theme provides opportunity for the 'social butterflies' who have 
been found to participate in charity sport events (Scott \& Solomon, 2003). The notion of event managers looking to allow participants to meet new people reflects an understanding of the impact of external socialisation (i.e., meeting new people) on an event experience (Nordvall, Pettersson, Svensson, \& Brown, 2014). Furthermore, event managers explicitly outlining how they created spaces and opportunities for interaction among participants embodies two of Chalip's (2006) strategies for developing sense of community through events: enabling sociability and informal social opportunities. These strategies involve allowing participants to share time, space and activities in and around the event, as well as the use of space on the event site in which participants can interact. The interactive event environment outlined by event managers directly reflects this. Overall, this theme reinforces the idea that interaction among event attendees is critical for creating value within the sport event experience (Woratschek, Durchholz, Maier, \& Ströbel, 2017). Furthermore, the event as a mechanism to bring people together reflects the notion that togetherness is highly valued within Japanese culture (Kim \& Lee, 2000).

The theme of supplementary activities shares similarities with social spaces as identified by Warner et al. (2013). Social spaces involve activities and areas in which socialising among participants is facilitated (Warner \& Dixon, 2011). Again, this theme encompasses strategies outlined by Chalip (2006). Specifically, event-related social activities and ancillary events refer to planned initiatives outside of the sport event and complementary activities that bring people together outside of the sport context. These programs reflect the novel activities such as dance competitions, novel dress, and photo booths described by the event managers interviewed. This theme also underscores the importance of social activities in creating a more inspiring event experience (Woolf et al., 2013). 
The final theme of lack of competition runs counter to previous literature suggesting that competition among participants brings them together and strengthens sense of community (Warner \& Dixon, 2011; Warner et al., 2013). Event managers described how they were proactive in communicating that their event was not a competition, and specifically designed the event to discourage competition, and encourage fun. The lack of competition contradicts participant motives such as physical, which have been shown to contribute to communitas among charity sport event participants (Filo et al., 2008), as well as the notion of competency, which contributes to a meaningful charity sport event experience (Filo et al., 2009). This also goes against the suggestion that charity sport event participants may get involved in an event to see how fast they can complete the activity (Coghlan \& Filo, 2013). However, event manager's emphasis on facilitating fun reinforces the importance of noyelty and play within the charity sport event experience (Filo \& Coghlan, 2016). This also supports the suggestion that charity sport events can attract less serious sport participants (Coghlan, 2014). Notably, a lack of competition reflects Japanese culture where competition is avoided and cooperation is valued (Hong, Muderrisoglu, \& Zinkhan, 1987). The data aligns with this and represents a distinction from charity sport events hosted in Western contexts.

While lack of competition deviated from Warner et al.'s (2013) conceptualisation, two additional themes from the framework were not evident in the interviews: common interest and leadership opportunities. The lack of competition inherent to the events examined within the current research may align with the notion that common interest was not discussed within the interviews. A shared enthusiasm for the physical activity within a charity sport event has been previously revealed to drive event participation (Filo et al., 2009; Wood, Snelgrove, \& Danylchuk, 2010), however the more informal and novel atmosphere promoted at the events 
examined may have led to less emphasis on the fostering passion for the sport. The absence of discussion surrounding leadership opportunities is notable as research has underscored how team leaders have a critical role in the charity sport event experience (Filo et al., 2018). This highlights a potential opportunity for event managers to identify and engage with these individuals to assist in fostering community among participants.

\section{Managerial Implications}

The results present a number of implications for charity sport event managers. First, while the themes uncovered reveal a variety of effective strategies employed by event managers to build sense of community within their events, effort can be made to aetivate the two themes that did not emerge from the data. Common interest can be leveraged through participants' collective experience training for the event. Event organisers can create an online discussion forum to allow individuals to share their experiences preparing for the event. In addition, mobile applications such as Strava can be integrated to connect participants in advance of the event to share their interests and insights. Since most events examined promoted a non-competitive and often novel event atmosphere, this sharing of training insights should be framed as a means to create knowledge. This is particularly relevant since non-traditional event participants have been shown to place greater emphasis on sharing a mutual interest with other participants (Buning \& Walker, 2016).

Second, promoting leadership opportunities among participants can address concerns regarding placing too much responsibility for maximising social impacts of sport events on event organisers (Chalip et al., 2016). Select participants can be identified and recruited as ambassadors or advocates for the event, cause and community. Recruitment of these potential leaders can be based upon their fundraising achievements, frequency of posting on the 
aforementioned discussion forums, or the length of their tenure as a participant. These participant leaders can then collaborate with event management (Taks, Chalip, \& Green, 2015) to activate the themes revealed in the current research by further educating other participants about the charity and their contribution, urge individuals to meet new people throughout the event experience, and encouraging participants to share their opinion of the event with the management team. These participant leaders could represent a valuable resource for facilitating a sense of community within charity sport events.

Third, the difficulties in collecting feedback from event participants in an efficient manner suggests that a more strategic approach is necessary. The event managers interviewed described how social networking sites such as Facebook and Instagram were utilised to solicit input from event participants before, during and after the event. However, there was a lack of clarity in terms of which platform was most relevant to participants, as well as resource challenges in managing these tools. Events with a defined social media strategy report higher revenue (Rothschild, 2011). To this end, staffing needs must be addressed to ensure that social media platforms are optimised as tools to collect participant attitudes and opinions. In addition, select event managers described how post-event questionnaires were employed to collect feedback, but some experienced issues with limited response rate. To address this, incentives can be utilised in an effort to increase response rate. In addition, in person interviews with participants to confront non-response to the questionnaires is suggested (Baruch \& Holtom, 2008).

\section{Limitations}

Limitations of the current research need to be acknowledged. First, this research represents data collected at a specific point in time. The recent natural disasters in Japan may 
have heightened awareness of charitable initiatives and increased their perceived importance among practitioners. In addition, Japan is currently preparing to host a collection of large-scale sport events (e.g., 2020 Olympics and Paralympics, Tokyo Rugby World Cup 2019, Swimming World Cup 2017), and this may have enhanced the significance of sport events in event manager's minds. These contextual elements could have potentially influenced the event managers' descriptions of their events and impacts. In addition, purposive sampling was utilised, however this was deemed appropriate due to the relatively limited number of charity sport events in Japan.

Second, while Japanese culture has been confronted with increasing frequency of social isolation, or hikikomori, among residents (Norasakkunkit \& Uchida, 2014), the country does represent a more collectivist culture (Triandis, Bontempo, Villareal, Asai, \& Lucca, 1988). These cultural nuances could have impacted the data, and in particular, the focus on collectivism in Japanese culture could have led the event managers to describe their events and participants in more harmonious and communal terms.

Third, while the current research represents an initial effort to incorporate the perspectives of additional charity sport event stakeholders, this work still represents data collected from a single group: event managers. The charity sport event managers were unanimously positive in describing their events, and the specific initiatives they had designed to build sense of community. However, the data were limited in that participant attitudes towards the events and activities was not included. Furthermore, additional charity sport event stakeholders such as event sponsors, local government representatives, and charity employees, each of whom were referenced within the interviews, were not incorporated in the data collection. This narrow focus in perspective represents a limitation of the current research. 


\section{Future Directions}

Based upon the foundation of the results of the current research, as well as the limitations identified above, a number of future studies can be designed and implemented. First, longitudinal data can be collected from event managers to address the fact that the current research was cross-sectional. Data can be collected from event managers before and after an event to inventory the different initiatives put in place to foster sense of community, as well as to evaluate their effectiveness. In addition, data can be collected from these same event managers in the years that follow to assess the strength of the ties within the community, and whether the community of participants sustains over time.

Second, interviews with charity sport event managers can be conducted in more individualistic cultures such as the United States and Australia. As noted above, the current research responds to calls for investigation of charity sport events from perspectives beyond event participants (e.g., Coghlan, 2012; Woolf et al., 2013). Continuing to collect data from event managers is encouraged to better understand the effort put forth to foster community and deliver meaningful event experiences. This data can complement the array of research investigating participant attitudes towards these events. In addition, collecting data from event managers in different countries can address concerns about the influence of cultural context on interviewees.

Third, additional charity sport event stakeholder perspectives can be integrated into a single study. Qualitative data collected from event managers can be complemented by quantitative data from event participants assessing the effectiveness of management strategies for building community, as well as assessing the strength of the sense of community. In addition, staff members working for the benefitting charities can be interviewed as well, to determine 
whether the sense of community derived from the events is a tool that can be used to further advance the charity's mission. Also, data can be collected from local council representatives and government officials to determine whether these events align with additional initiatives within the locality to strengthen the community and improve health and wellbeing.

\section{CONCLUSION}

The current research was conducted to advance understanding of the sense of community derived from charity sport events from the perspective of event managers in Japan. Specifically, the following research question was addressed: What do charity sport event managers feel they have put in place to create sense of community among participants? Five themes were described by event managers: charitable contribution, soliciting feedback from participants, interactive event environment, supplementary activities, and lack of competition. These themes share similarities with existing research on sense of community in sport (e.g., Chalip, 2006; Warner \& Dixon, 2011; Warner et al., 2013), while differences were also revealed. It is hoped that the current research serves as a starting point for diversifying the viewpoints from which charity sport event knowledge is informed. 


\section{APPENDIX}

Sense of Community through Charity Sport Events: An Event Manager Perspective -

\section{Interview Guide}

Event:

\section{Biographical:}

Name:

$\begin{array}{lllll}\text { Age: } & \mathbf{1 8 - 2 4} & \mathbf{2 5 - 3 4} & \mathbf{3 5 - 4 5} & \mathbf{4 6 - 6 0}\end{array}$

Education Level:

Less than High School High School Bachelors Postgraduate Professional Degree

Working Period:

How long did you work for this charity event?

) years

Occupation:

If you have another full time job, what do you dô?

\section{Interview Questions:}

- [Common Interest] Do you utilise people's interest in <event activity $>$ to bring participants together? If so, how?

- [Social Spaces] How do you design your event to facilitate interaction and socialising among event participants?

- [Leadership Opportunity] How would you describe your efforts to solicit opinions from event participants on how the event is designed and delivered?

- [Equity of Administrative Decisions] Please describe how decisions are made within your event management team and how you ensure that the decisions benefit the most amount of people?

- [Common Interest] Please provide an example of how the event management team promotes a sense of belonging among event participants?

- [Administrative Considerations] How would you describe the communication between the event management team and event participants? 
- Can you provide an example of how you interact directly with participants during the event delivery? (This means before, during, and after the event. Basically, from the time that participants register to the time the event concludes.)

- Overall, do you feel that there is a strong bond among participants in your event? Please describe the details.

- How important is it for your event management team to build community through this event?

- What are the most important objectives for the event from your perspective (from the perspective as an event manager)?

- What do you feel (from the perspective as an event manager) is the best aspect of your event?

- What kind of difficulty are you feeling to organize your charity event? 


\section{REFERENCES}

Baruch, Y., \& Holtom, B. C. (2008). Survey response rate levels and trends in organizational research. Human Relations, 61(8), 1139-1160.

Bennett, R., Mousley, W., Kitchin, P., \& Ali-Choudhury, R. (2007). Motivations for participating in charity-affiliated sporting events. Journal of Customer Behaviour, 6(2), 155-178.

Braun, V., \& Clarke, V. (2006). Using thematic analysis in psychology. Qualitative Research in Psychology, 3, 77-101.

Bunds, K. S., Brandon-Lai, S., \& Armstrong, C. (2016). An inductive investigation of participants' attachment to charity sports events: the case of team water charity. European Sport Management Quarterly, 16(3), 364-383.

Buning, R. J., \& Walker, M. (2016). Differentiating mass participant sport event consumers: Traditional versus non-traditional events. Sport Marketing Quarterly, 25(1), 47.

Cha, V. (2016). Role of sport in international relations: National rebirth and renewal. Asian Economic Policy Review, 11(1), 139-155.

Chalip, L. (2006). Towards social leverage of sport events. Journal of Sport \& Tourism, 11, 109127.

Chalip, L., Green, B. C., Taks, M., \& Misener, L. (2016). Creating sport participation from sport events: Making it happen. International Journal of Sport Policy and Politics, 9, 1-20.

Charity Aid Foundation. (2016). World Giving Index. Retrieved 8 August, 2017 from: https://www.cafonline.org/about-us/publications/2016-publications/caf-world-giving$\underline{\text { index-2016 }}$ 
Charity Aid Foundation. (2017). World Giving Index. Retrieved 29 December, 2017 from: https://www.cafonline.org/about-us/publications/2017-publications/caf-world-giving$\underline{\text { index-2017 }}$

Chavis, D. M., \& Wandersman, A. (1990). Sense of community in the urban environment: A catalyst for participation and community development. American Journal of Community Psychology, 18(1), 55-81.

Clopton, A. W. (2008). College sports on campus: Uncovering the link between fan identification and sense of community. International Journal of Sport Management, 9(4), 343-362.

Coghlan, A. (2012). An autoethnographic account of a cyeling charity challenge event: Exploring manifest and latent aspects of the experience. Journal of Sport \& Tourism, $17(2), 105-124$.

Coghlan, A. (2014). Cycling charity challenge events: Can they contribute to the lifestyle medicine movement? Tourism Review International, 18(1), 87-98.

Coghlan, A., \& Filo, K. (2013). Using constant comparison method and qualitative data to understand participants' experiences at the nexus of tourism, sport and charity events. Tourism Mânagement, 35, 122-131.

Cova, B., \& Pace, S. (2006). Brand community of convenience products: New forms of customer empowerment-the case "my Nutella The Community". European Journal of Marketing, 40(9-10), 1087-1105.

Davidson, W. B., \& Cotter, P. R. (1991). The relationship between sense of community and subjective well-being: A first look. Journal of Community Psychology, 19(3), 246-253. 
Filo, K., \& Coghlan, A. (2016). Exploring the positive psychology domains of well-being activated through charity sport event experiences. Event Management, 20(2), 181-199.

Filo, K., Funk, D. C., \& O’Brien, D. (2008). It's really not about the bike: Exploring attraction and attachment to the events of the Lance Armstrong Foundation. Journal of Sport Management, 22(5), 501-525.

Filo, K., Funk, D. C., \& O’Brien, D. (2009). The meaning behind attachment: Exploring camaraderie, cause, and competency at a charity sport event. Journal of Sport Management, 23(3), 361-387.

Filo, K., Lock, D., Sherry, E., \& Quang Huynh, H. (2018). 'You belonged to something': exploring how fundraising teams add to the social leverage of events. European Sport Management Quarterly, 18(2), 216-236.

Filo, K., Spence, K., \& Sparvero, E. (2013). Exploring the properties of community among charity sport event participants. Managing Leisure, 1-19.

Goodwin, A., Snelgrove, R., Wood, L., \& Táks, M. (2017). Leveraging charity sport events to develop a connection to a cause. Event Management, 21(2), 175-184.

Hampton, K. N., Sessions, L. F., \& Her, E. J. (2011). Core networks, social isolation, and new media: How Internet and mobile phone use is related to network size and diversity. Information, Communication \& Society, 14(1), 130-155.

Harada, S. (2015). Policy processes in the 2011 revision of the nonprofit organization law in Japan: Based on the advocacy coalition framework. The Nonprofit Review, 15(1), 1-12.

Higgins, J. W., \& Lauzon, L. (2003). Finding the funds in fun runs: Exploring physical activity events as fundraising tools in the nonprofit sector. International Journal of Nonprofit and Voluntary Sector Marketing, 8(4), 363-377. 
Hong, J. W., Muderrisoglu, A., \& Zinkhan, G. M. (1987). Cultural differences and advertising expression: A comparative content analysis of Japanese and US magazine advertising. Journal of Advertising, 16(1), 55-68.

Jarvie, G. (2003). Communitarianism, sport and social capital. International Review for the Sociology of Sport, 38, 139-153.

Kerwin, S., Warner, S., Walker, M., \& Stevens, J. (2015). Exploring sense of community among small-scale sport event volunteers. European Sport Management Quarterly, 15(1), 7792.

Kim, C., \& Lee, S. (2000). Understanding the cultural differences in tourist motivation between Anglo-American and Japanese tourists. Journal of Travel \& Tourism Marketing, 9(1-2), 153-170.

Kurasaki, K. S. (2000). Intercoder reliability for validating conclusions drawn from open ended interview data. Field Methods, 12, 179-194.

Lankston, C. (2011). Japan bid for Olympics to aid tsunami recovery. Retrieved 24-July, 2017 from: http://www.telegraph.co.uk/sport/olympics/news/8640217/Japan-bid-for-Olympicsto-aid-tsunami-recovery.html

Lincoln, Y. S., \& Guba, E. G. (1985). Naturalistic inquiry. Newbury Park, CA: Sage.

McDonald, H., \& Karg, A. J. (2014). Managing co-creation in professional sports: The antecedents and consequences of ritualized spectator behavior. Sport Management Review, 17(3), 292-309.

McMillan, D. W., \& Chavis, D. M. (1986). Sense of community: A definition and theory. Journal of Community Psychology, 14(1), 6-23. 
McPherson, M., Smith-Lovin, L., \& Brashears, M. E. (2006). Social isolation in America:

Changes in core discussion networks over two decades. American Sociological Review, $71(3), 353-375$.

Miles, M. B., \& Huberman, A. M. (1994). Qualitative data analysis ( $2^{\text {nd }}$ Ed.). Thousand Oaks: Sage, London.

Misener, L., \& Mason, D. S. (2006). Creating community networks: Can sporting events offer meaningful sources of social capital? Managing Leisure, 11, 39-56

Mizumoto, T., \& Okumura, T. (2016). Agile development of disaster information systems for the Kumamoto Earthquake: How geeks should respond in deadly disaster situations. In Global Humanitarian Technology Conference (GHTC), 2016 (pp. 241-247). IEEE.

Norasakkunkit, V., \& Uchida, Y. (2014). To conform or to maintain self-consistency?

Hikikomori risk in Japan and the deviation from seeking harmony. Journal of Social and Clinical Psychology, 33(10), 918-935.

Nordvall, A., Pettersson, R., Svensson, B., \& Brown, S. (2014). Designing events for social interaction. Event Management, 18(2), 127-140.

Olberding, D. J., \& Jisha, J. (2005). The flying pig: Building brand equity in a major urban marathon. SportMarketing Quarterly, 14(3), 191-196.

Pasanen, K., \& Konu, H. (2016). Use of social media for new service development by Finnish event and festival organizers. Event Management, 20(3), 313-325.

Peachey, J. W., Borland, J., Lobpries, J., \& Cohen, A. (2015). Managing impact: Leveraging sacred spaces and community celebration to maximize social capital at a sport-fordevelopment event. Sport Management Review, 18(1), 86-98. 
Rabionet, S. E. (2011). How I learned to design and conduct semi-structured interviews: An ongoing and continuous journey. The Qualitative Report, 16(2), 563.

Ross, A., \& Searle, M. (2019). A conceptual model of leisure time physical activity, neighborhood environment, and sense of community. Environment and Behavior, $51(6), 749-781$.

Rothschild, P. C. (2011). Social media use in sports and entertainment venues. International Journal of Event and Festival Management, 2(2), 139-150.

Saito, E. \& Nakamura, Y. (2012). Efforts by the sports industry for reconstruction after the great east Japan earthquake disaster and the effects on people in the disaster area. Journal of Japan Society of Sports Industry, 22, 209-214.

Sarason, S. B. (1974). The psychological sense of community: Prospects for a community psychology. San Francisco: Jossey-Bass.

Scott, A., \& Solomon, P. J. (2003). The marketing of cause-related events: A study of participants as consumers. Journal of Nonprofit \& Public Sector Marketing, 11(2), 4366.

Su, C. T., \& Parham, L. D. (2002) Case report-generating a valid questionnaire translation for cross-cultural use. American Journal of Occupational Therapy, 56, 581-585.

Takenaka, Y. (2014). Load to expansion of the J-league. Bulletin of Aichi Institute of Technology, 49, 143-148.

Taks, M., Chalip, L., \& Green, B. C. (2015). Impacts and strategic outcomes from non-mega sport events for local communities. European Sport Management Quarterly, 15, 1-6. 
Triandis, H. C., Bontempo, R., Villareal, M. J., Asai, M., \& Lucca, N. (1988). Individualism and collectivism: Cross-cultural perspectives on self-in group relationships. Journal of Personality and Social Psychology, 54(2), 323.

Tonnies, F. (1974). Gemeinschaft and Gesellschaft. In C. Bell and H. Newby (Eds.), The sociology of community (pp. 185-213). London: Frank Cass.

Warner, S., \& Dixon, M. A. (2011). Understanding sense of community from the athlete's perspective. Journal of Sport Management, 25(3), 257-271.

Warner, S., Dixon, M. A., \& Chalip, L. (2012). The impact of formal versus informal sport: Mapping the differences in sense of community. Journal of Community Psychology, 40(8), 983-1003.

Warner, S., Dixon, M., \& Leierer, S. (2015). Using youth sport to enhance parents' sense of community. Journal of Applied Sport Management, 7(1), 45-63.

Warner, S., Kerwin, S., \& Walker, M. (2013), Examining sense of community in sport: Developing the multidimensional 'SCS' Scale. Journal of Sport Management, 27(5), $349-362$.

Wood, L., Snelgrove, R. and Danylchuk, K. (2010). Segmenting volunteer fundraisers at a charity sport event. Journal of Nonprofit and Public Sector Marketing, 22(1), 38-54.

Woolf, J., Heere, B., \& Walker, M. (2013). Do charity sport events function as "Brandfests" in the development of brand community? Journal of Sport Management, 27(2), 95-107.

Woratschek, H., Durchholz, C., Maier, C., \& Ströbel, T. (2017). Innovations in sport management: The role of motivations and value cocreation at public viewing events. Event Management, 21(1), 1-12. 
Woratschek, H., Horbel, C., \& Popp, B. (2014). The sport value framework-A new fundamental logic for analyses in sport management. European Sport Management Quarterly, 14, 624.

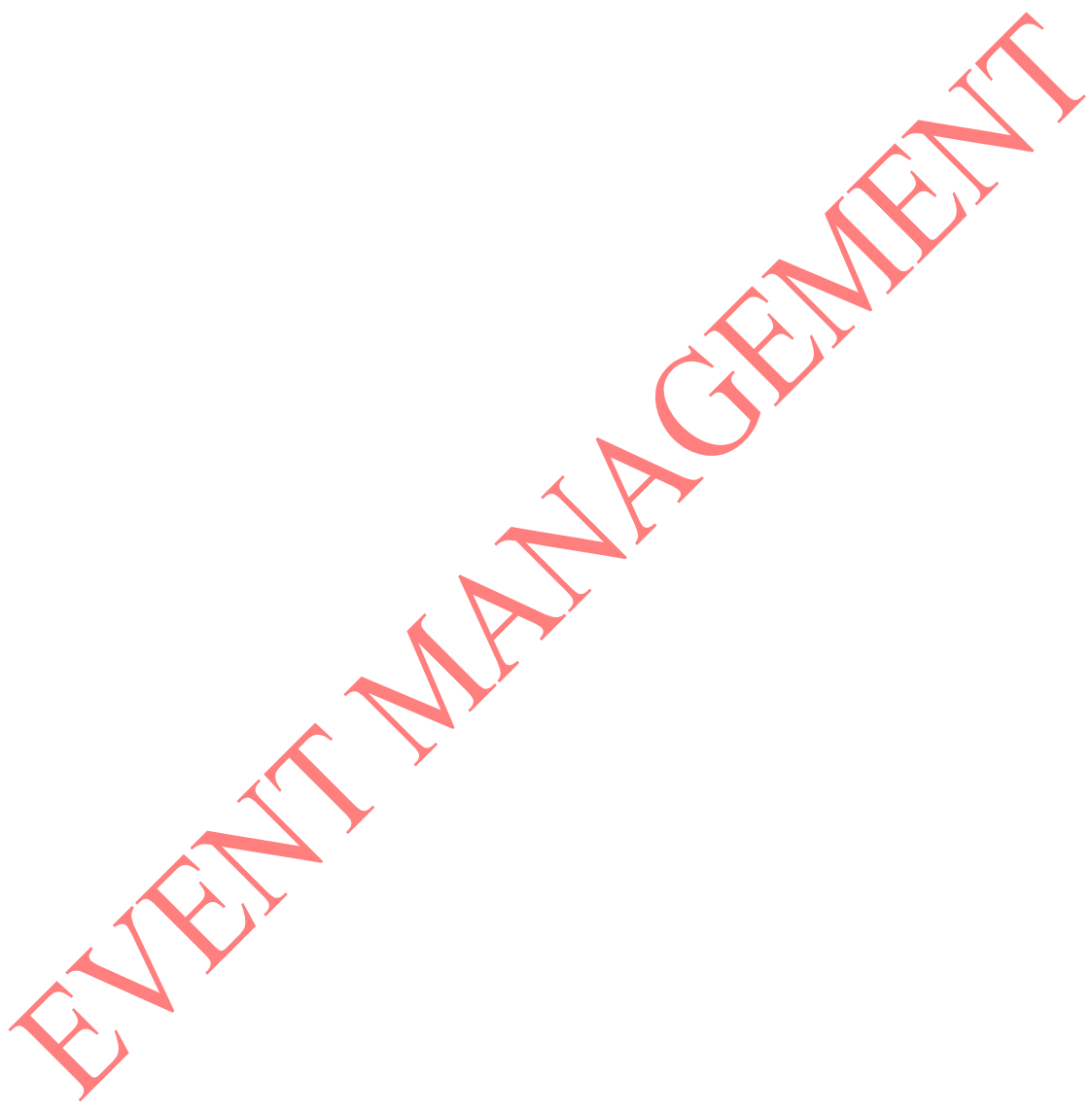




\section{Table 1}

Event Manager Demographics, Event History, Activity and Benefiting Charities for Each Event

\begin{tabular}{|c|c|c|c|}
\hline $\begin{array}{l}\text { Gender of } \\
\text { Interviewee }\end{array}$ & $\begin{array}{l}\text { First Year } \\
\text { of Event }\end{array}$ & Sport Activity & Benefitting Charity (or Charities) \\
\hline Male & 2016 & Run & $\begin{array}{l}\text { Japanese Red Cross, Kumamoto } \\
\text { contribution, Ooita contribution }\end{array}$ \\
\hline Male & 2015 & Run & Local social welfare organisation \\
\hline Male & 2009 & $\begin{array}{l}\text { Sport Festival } \\
(6 \text { sports })\end{array}$ & $\begin{array}{l}\text { EDF (Education for Development } \\
\text { Foundation) Japan }\end{array}$ \\
\hline Female & 2014 & Run & Japan Association for Refugees \\
\hline Male & 2005 & Run & $\begin{array}{l}8 \text { selected charity organisations (e.g. } \\
\text { Paralympian Association of Japan) }\end{array}$ \\
\hline Male & 2011 & Run & Kindergartens in Fukushima area \\
\hline Male & 2002 & & Japan Society of Breast Health \\
\hline Female & 2016 & & $\begin{array}{l}\text { Women's Support project in Nepal, } \\
\text { Ghana and Zambia }\end{array}$ \\
\hline Female & 2009 & & Hospitals in and around the Kansai area \\
\hline Female & & Walk and Run & Japan Cancer Society \\
\hline Male \& Female & & Futsal & Sister Organization in Ghana \\
\hline Male & & Run & $\begin{array}{l}\text { Subsidiaries who provide after-school } \\
\text { activities for disabled children }\end{array}$ \\
\hline Female & 2010 & Run & $\begin{array}{l}\text { JOICFP The supply centre of school } \\
\text { meals in Kumamoto }\end{array}$ \\
\hline Female & 2005 & Run & Filipino Child Care House \\
\hline Male & 2011 & Run & $\begin{array}{l}\text { University } \\
\text { Volunteer Group for Hurricane } \\
\text { Reconstruction }\end{array}$ \\
\hline
\end{tabular}

